\title{
Sustained Effects of Platelet-Activating Factor Infusion in Piglets ${ }^{1}$
}

\author{
JOSEPH J. STAMBOULY, LINDA M. BRADLEY, JOHN F. CZAJA, AND ROBERT E. GOLDSTEIN
}

Department of Anesthesiology (Critical Care Medicine), Children's National Medical Center and George Washington University School of Medicine, Washington, District of Columbia 20010 [J.J.S., L.M.B.] and Department of Medicine (Division of Cardiology), Uniformed Services University of the Health Sciences, Bethesda, Maryland 20814-4799 [L.M.B., J.F.C., R.E.G.]

\begin{abstract}
Acute exposure to platelet-activating factor (PAF) causes severe pulmonary vasoconstriction (PV), but its action may be markedly limited by tachyphylaxis. To determine the effects of PAF exposure per se and the effects compared with the hypoxemic state $(33 \pm 1 \mathrm{~mm} \mathrm{Hg})$, PAF infusions $(0.05-0.15 \mathrm{nmol} / \mathrm{kg} / \mathrm{min} \times 30-180 \mathrm{~min})$ were administered to 15 open-chested, anesthetized, neonatal piglets before and during administration of selective receptor blockers to PAF (SRI $63441,5 \mathrm{mg} / \mathrm{kg}$ i.v. or WEB $2086,10 \mathrm{mg} / \mathrm{kg}$ i.v.) or vehicle. Measurements included mean pulmonary (PAP) and systemic arterial pressures, cardiac index, right and left ventricular pressures and dimensions, and coronary blood flow. Mean PAP and pulmonary vascular resistance index rose in response to 30 min PAF infusion $(14 \pm 1$ to $30 \pm 1 \mathrm{~mm} \mathrm{Hg}$ and $4500 \pm$ 700 to $16400 \pm 1900$ dynes $\mathrm{s} \mathrm{cm}^{-5} \cdot \mathrm{kg}$, both $p<0.01, n$ $=10$ ). Similar changes occurred when PAF was infused for $180 \min (n=5)$. Other parameters were unaffected. Acute hypoxia also increased in PAP and pulmonary vascular resistance index $(17 \pm 1$ to $32 \pm 2 \mathrm{~mm} \mathrm{Hg}$ and 6400 \pm 900 to $17100 \pm 1800$ dynes $\mathrm{s} \mathrm{cm}^{-5} \cdot \mathrm{kg}$, both $p<0.01$ ) and did not alter other measured variables. Treatment with SRI 63441 prevented PAF-induced increases in PAP (14 \pm 1 to $14 \pm 1 \mathrm{~mm} \mathrm{Hg}, p<0.05)$ and pulmonary vascular resistance index $\left(5300 \pm 900\right.$ to $5500 \pm 800$ dynes $\mathrm{s} \mathrm{cm}^{-5}$. $\mathrm{kg}, p<0.05$ ) but failed to alter the response to hypoxia. SRI 63441 and WEB 2086, administered during PAF infusion, rapidly reversed PAF action. Vehicle had no effect. We conclude that PAF can produce severe and sustained $\mathrm{PV}$ in vivo and that $\mathrm{PAF}$ receptor blockade may be useful in treatment of neonatal disease featuring PAFmediated PV. PAF receptors may not be involved in PV induced by hypoxia. (Pediatr Res 30: 261-265, 1991)
\end{abstract}

\section{Abbreviations}

PAF, platelet activating factor (1-0-hexadecyl-2-acetyl-snglyceryl-3-phosphocholine)

PAP, mean pulmonary artery pressure

PVRI, pulmonary vascular resistance index

Received July 27, 1990; accepted April 30, 1991

Correspondence and reprint requests: Linda M. Bradley, M.D., Division of Cardiology, Department of Medicine, A-3060, USUHS, 4301 Jones Bridge Road, Bethesda, MD 20814-4799.

Supported by U.S.U.H.S. Grant No. R08346. L.M.B. was supported by a training fellowship from the American Heart Association, Maryland Affiliate, Inc.

The opinions or assertions contained here are the private ones of the authors and are not to be construed as official or representing the view of the Department of Defense or the Uniformed Services University of the Health Sciences. The experiments reported here were conduced according to the principles set forth in the Guide for Care and Use of Laboratory Animals, Institute of Laboratory Animal Resources, National Resource Council, DHEW publ. no. (NIH) 80-23.
Diseases featuring marked pulmonary vasoconstriction remain a major source of morbidity and mortality in newborns $(1,2)$, yet the pathophysiologic mechanisms of this dysfunction remain unclear (3). These diseases frequently involve inflammatory events in the lung (e.g. aspiration) with accompanying leukocyte accumulation and tissue macrophage activation. Recent research has implicated inflammatory mediators (4-9), particularly PAF $(8,9)$ in the pathogenesis of pulmonary vasoconstriction in newborns of several species. Experimental findings in adult animals have confirmed the capacity of PAF to produce profound circulatory derangements, including severe increases in pulmonary vascular resistance with right ventricular failure and hypotension $(10,11)$, decreased coronary blood flow $(12,13)$, myocardial dysfunction $(14,15)$, and sudden death (16). However, studies demonstrating adverse effects of PAF on the cardiovascular system have generally used bolus dosing. Whether sustained PAF exposure produces continuing hemodynamic abnormalities is unknown. Significant tachyphylaxis to repeated PAF dosing occurs in vitro (17) and in some models in vivo $(18,19)$. Demonstration of an ongoing responsiveness to PAF in vivo is necessary if PAF is to be included among the mediators of important pathophysiologic events in newborns. In addition, it would be useful to know whether sustained PAF efficacy is readily reversed by cessation of exposure or blockade. In vivo, it is possible that PAF could initiate a chain of events in the circulatory system that is not reversible.

This study was undertaken to evaluate the circulatory effects of sustained PAF infusion in a neonatal animal model and to determine the extent to which its action could be prevented or reversed by PAF discontinuation or PAF receptor antagonism with two structurally unrelated blockers. The pulmonary vasoconstrictor efficacy of PAF was compared with that of hypoxia, an intervention that does not exhibit tachyphylaxis.

\section{MATERIALS AND METHODS}

Preparation. Fifteen neonatal domestic piglets (Hampshire strain) of both sexes, aged 7-14 d, were used in this study. The average weight was $2.6 \pm 0.1 \mathrm{~kg}$.

Piglets were sedated with intramuscular ketamine hydrochloride $(20 \mathrm{mg} / \mathrm{kg})$ and anesthetized with i.v. sodium pentobarbital $(30 \mathrm{mg} / \mathrm{kg}$ ). A tracheostomy was performed, and a $3.5-\mathrm{mm}$ endotracheal tube was placed. The animals were then mechanically ventilated with an infant ventilator (model no. 665; Harvard Apparatus, South Natick, MA). Ventilator settings and inspired oxygen were initially adjusted to maintain arterial $\mathrm{pH}$ at 7.38$7.42, \mathrm{PO}_{2}$ at $90-100 \mathrm{~mm} \mathrm{Hg}(12-13 \mathrm{kPa})$ and $\mathrm{PCO}_{2}$ at $35-45 \mathrm{~mm}$ $\mathrm{Hg}(5-6 \mathrm{kPa})$. Body temperature was kept between 36.6 and $38.0^{\circ} \mathrm{C}$ by an external heating blanket. Polyvinyl catheters were placed in the left external jugular vein and carotid artery. A left lateral thoracotomy was performed and the heart was suspended in a pericardial cradle. Two-mm (outer diameter) polyvinyl 
catheters were then placed in the right ventricle and the main pulmonary artery via small stab incisions. A 4-French high fidelity pressure catheter (Millar Instruments, Houston, TX) was similarly placed in the left ventricle. Because the ductus arteriosus is not patent in this preparation (8), a calibrated electromagnetic flow transducer (Carolina Medical Electronics, King, NC) was placed around the proximal portion of the main pulmonary artery to measure cardiac output. A miniaturized Doppler flow probe (Valpey-Fisher, Hopkinton, MA) was placed around an exposed midportion of the left anterior descending coronary artery, using previously described techniques in similar-sized blood vessels (20), and connected to a pulsed Doppler flowmeter (University of Iowa, Bioelectrical Engineering, Iowa City, IA). Output signals (flow-proportional Doppler shifts) were recorded continuously. Pairs of 3-mm ultrasonic crystals (Dimension 3, Cardiff-by-Sea, CA) were embedded in the epicardial surface of the left ventricle, to continuously measure myocardial segment length using appropriate signal processing instrumentation (Sonomicrometer 120, Triton Technology, San Diego, CA). Vascular pressures, measured with fluid-filled transducers (model no. P23 ID; Gould-Statham Instruments, Hato Rey, PR) were recorded on a multichannel recorder (model no. 7758A; Hewlett-Packard Instruments, Rockville, MD). A surface ECG was also recorded.

Baseline hemodynamic measurements were determined to be stable for at least 30 min after instrumentation of all animals.

Protocol $1(n=10)$. After baseline arterial blood gas determination, $\mathrm{Hb}$, hematocrit, and hemodynamic measurements, animals were given either PAF or hypoxia in random order. PAF, $0.05 \mathrm{nmol} / \mathrm{kg} / \mathrm{min}$, was given by continuous infusion into the left external jugular vein. PAF dose was increased in 2-fold increments every $3 \mathrm{~min}$ to elevate mean PAP to at least twice baseline value. Infusion rate was held constant for $30 \mathrm{~min}$ and then discontinued. After a 30 -min recovery period and repeat baseline measurements, animals were ventilated with $12 \% \mathrm{O}_{2}$ and $88 \% \mathrm{~N}_{2}$ for $3 \mathrm{~min}$. Arterial blood gas content was measured, and hypoxia was discontinued.

Piglets were then randomized to receive either the PAF receptor blocker SRI $63441(5 \mathrm{mg} / \mathrm{kg}$ i.v. bolus, $n=4)$ or an equal volume of vehicle for this agent, $0.9 \% \mathrm{NaCl}(n=6)$. The dose of SRI 63441 was based on previous in vivo studies that showed maximal antagonistic capacity in a variety of species $(21,22)$. Thirty min later, hypoxia and a repeat PAF infusion (as described above) were given in random order. For each animal, PAF was infused at the same peak dose used during the first infusion; the initial dose-finding phase of the first PAF infusion was not repeated. To determine reversibility of PAF action, four of the six control animals received SRI $63441(5 \mathrm{mg} / \mathrm{kg}$ i.v. bolus) 20 min after initiation of the repeat PAF infusion. At the conclusion of the study, animals were given a sodium pentothal overdose and a lethal $\mathrm{KCl}$ injection.

Protocol $2(n=5)$. After baseline measurements, PAF 0.05 $\mathrm{nmol} / \mathrm{kg} / \mathrm{min}$ was given by continuous infusion as in protocol 1 , increasing the dose in 2-fold increments to achieve mean PAP of at least twice baseline value. Infusion rate was held constant for $120 \mathrm{~min}$. At $120 \mathrm{~min}$, either the selective PAF receptor blocker WEB $2086(10 \mathrm{mg} / \mathrm{kg}$ i.v. bolus, $n=2)$ or an equal volume of vehicle $(n=3)$ was given. The dose of WEB 2086 was based on previous studies that confirmed maximal antagonistic capacity in several models (23). PAF infusion was continued for an additional $60 \mathrm{~min}$. At $180 \mathrm{~min}, \mathrm{PAF}$ infusion was discontinued. Animals were allowed a $15-30$ min recovery period. Baseline measurements were repeated, and animals were ventilated with $12 \% \mathrm{O}_{2}$ and $88 \% \mathrm{~N}_{2}$ for $15 \mathrm{~min}$. At $15 \mathrm{~min}$, arterial blood gas content was measured, and PAF $0.1 \mathrm{nmol} / \mathrm{kg}$ i.v. bolus was injected. Hemodynamic data was recorded for an additional 15 min. Animals were then killed as in protocol 1.

Drugs. Pure synthetic PAF (1-0-hexadecyl-2-acetyl-sn-glycero3-phosphocholine, kindly provided by Dr. F. Snyder, Oak Ridge Associated Universities, Oak Ridge, TN) was dissolved in $0.9 \%$ $\mathrm{NaCl}$ to a concentration of $1 \mathrm{nmol} / 10 \mu \mathrm{L}$ and kept in frozen aliquots at $-70^{\circ} \mathrm{C}$ until used. Each aliquot was thawed only once and diluted with $0.9 \% \mathrm{NaCl}$ to the desired final concentration.

Pure SRI 63441 was kindly provided by Dr. Dean Handley, Sandoz Research Institute, East Hanover, NJ. It was kept refrigerated at $4^{\circ} \mathrm{C}$, and then dissolved immediately before use in $0.9 \%$ $\mathrm{NaCl}$.

Pure WEB $208650 \mathrm{mg}$ (generously donated by Dr. Hubert Heuer, Boehringer-Ingelheim, Ingelheim am Rhein, Germany) was dissolved in $3 \mathrm{~mL} 0.1 \mathrm{~N} \mathrm{HCl}$ with $2.3 \mathrm{~mL} 0.1 \mathrm{NaOH}$. The solution was then diluted with $0.9 \% \mathrm{NaCl}$ to a volume of $10 \mathrm{~mL}$. $\mathrm{pH}$ was titrated with $0.1 \mathrm{~N} \mathrm{NaOH}$ to a final $\mathrm{pH}$ of 6.0-6.4.

Data analysis. All data were continuously recorded; those from mid- to end-expiration were chosen for analysis; the respirator was not stopped at any point. Pulmonary flow was assumed to approximate cardiac output $(\mathrm{mL} / \mathrm{min})$. Cardiac index (CI) was calculated as cardiac output/weight $(\mathrm{kg})$; systemic vascular resistance index (SVRI) was calculated as $80 \times$ [mean arterial pressure (MAP) - right ventricular end-diastolic pressure]/Cl; and the pulmonary PVRI was calculated as $80 \times$ (PAP - left ventricular end-diastolic pressure)/Cl. Ventricular segment lengths and shortening fractions were assessed using standard methods.

Results obtained during the first PAF infusion (protocol 1) were pooled for all 10 animals because the four later given SRI 63441 responded in the same manner as the six later given vehicle. Data are presented as mean values \pm SEM for the indicated number of piglets. One-way analysis of variance followed by the Student-Newman Keuls test for multiple comparison was used for statistical evaluation. Differences were considered significant when $p<0.05$.

\section{RESULTS}

Protocol 1. Effects of PAF infusion before and after SRI 63441 or vehicle. Continuous infusion of PAF $(0.12 \pm 0.01 \mathrm{nmol} / \mathrm{kg} /$ min, $n=10$ ) produced significant increases in PAP $[14 \pm 1$ to $30 \pm 1 \mathrm{~mm} \mathrm{Hg}$ (at $3 \mathrm{~min}), p<0.01]$ and PVRI $[4.5 \pm 0.7$ to $16.4 \pm 1.9$ dynes s cm $\mathrm{sm}^{-5} \cdot \mathrm{kg} \times 10^{-3}$ (at $\left.\left.3 \mathrm{~min}\right), p<0.01\right]$. The PAF-induced rise in PAP and PVRI reached peak levels at $3 \mathrm{~min}$ and remained constant for the duration of infusion (Fig. 1). The values for PAP and PVRI returned to baseline within 5 min after discontinuation of the PAF infusion. Mean systemic arterial pressure, systemic vascular resistance index, cardiac index, and coronary blood flow did not significantly change in response to PAF infusion (Table 1). Similarly, PAF administration did not change right and left ventricular end-diastolic pressure from pretreatment baseline ( $7 \pm 1$ to $9 \pm 1$ and $8 \pm 1$ to $8 \pm 1 \mathrm{~mm}$ $\mathrm{Hg})$, nor did it alter left ventricular fractional shortening (17 \pm 1 to $17 \pm 1$ and $17 \pm 1$ to $14 \pm 1 \%$, both NS). SRI 63441 had no effect on baseline mean arterial pressure $(57 \pm 4$ versus $52 \pm$ $5 \mathrm{~mm} \mathrm{Hg})$, PAP $(13 \pm 1$ versus $15 \pm 2 \mathrm{~mm} \mathrm{Hg})$, or cardiac index $(110 \pm 6$ versus $120 \pm 8 \mathrm{~mL} / \mathrm{kg} / \mathrm{min})$ when compared with vehicle. However, PAF receptor antagonism with SRI 63441 completely inhibited the PAF-induced rise in PAP $14 \pm 1$ to 14 $\pm 1 \mathrm{~mm} \mathrm{Hg}$ and PVRI $\left(5.3 \pm 0.9\right.$ to $5.5 \pm 0.8$ dyne $\mathrm{s} \mathrm{cm}^{-5} \cdot \mathrm{kg}$ $\times 10^{-3}$ ) (Fig. 1). During the repeat PAF infusion, vehicle for SRI 63441 did not significantly attenuate PAF-induced hemodynamic displacements from pre-PAF baselines (PAP $15 \pm 2$ to 30 $\pm 2 \mathrm{~mm} \mathrm{Hg}$ and PVRI $4.8 \pm 0.8$ to $16.7 \pm 2.1$ dynes $\mathrm{s} \mathrm{cm}^{-5} \cdot \mathrm{kg}$ $\times 10^{-3}$, both $p<0.01$ ). When SRI 63441 was given to four of six vehicle-treated control animals after $20 \mathrm{~min}$ of PAF-induced pulmonary hypertension, PAP and PVRI decreased immediately, returning to pre-PAF baseline levels within $10 \mathrm{~min}$, in contrast to the remaining two animals, which continued as vehicle-treated controls (Fig. 2): PAP $29 \pm 2$ fell to $12 \pm 1 \mathrm{~mm}$ $\mathrm{Hg}$ and PVRI $15.2 \pm 0.8$ fell to $4 \pm 0.2$ dynes $\mathrm{s} \mathrm{cm}^{-5} \cdot \mathrm{kg} \times 10^{-3}$ (both $p<0.05$ ).

Effects of acute hypoxia before and after SRI 63441 or vehicle. Initial administration of hypoxia $(n=10)$ produced marked hypoxemia without altering $\mathrm{pH}$ or $\mathrm{PCO}_{2}$ [baseline $\mathrm{pH} 7.38 \pm$ 

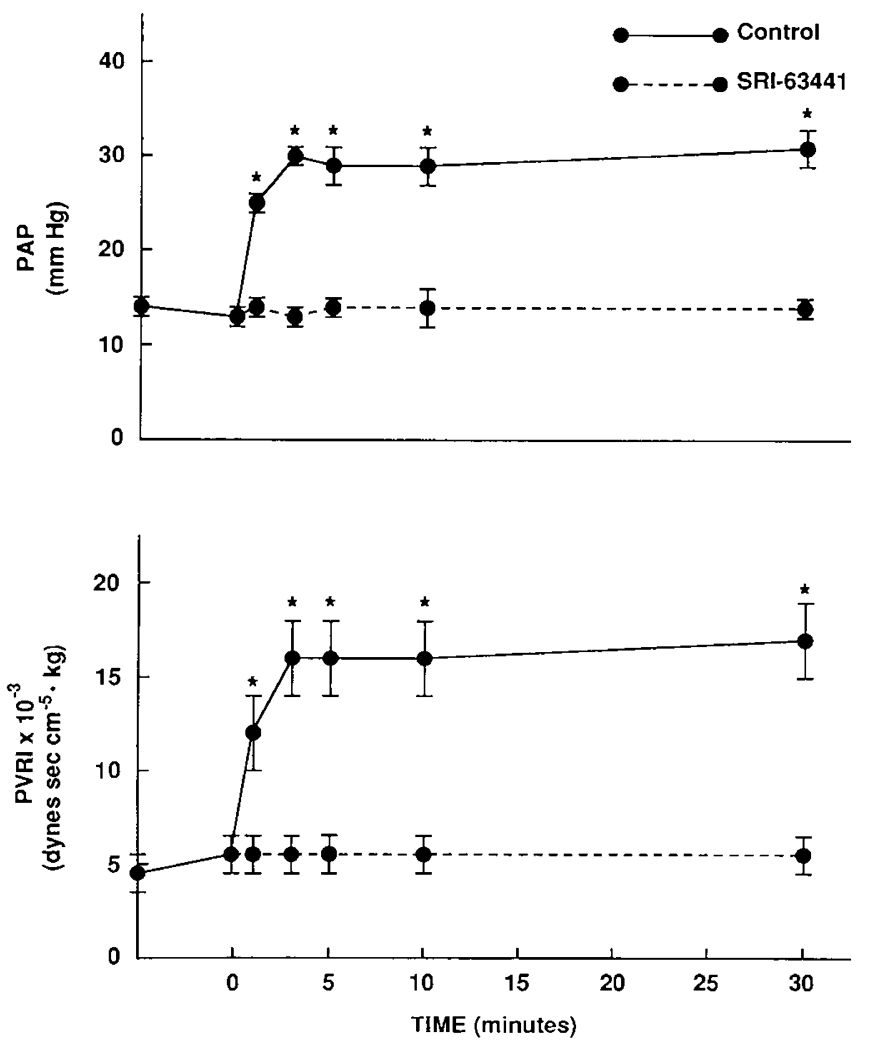

Fig. 1. Pulmonary vascular effects of an initial, sustained PAF infusion $(n=10)$ and a repeat of the same PAF infusion after treatment with SRI $63441(n=4)$. In the absence of SRI 63441 , PAF $(0.12 \pm 0.01$ $\mathrm{nmol} / \mathrm{kg} / \mathrm{min}$ ) caused significant increases in PAP and PVRI when compared with pre-PAF baseline. PAP and PVRI reached peak values at $3 \mathrm{~min}$ and remained constant for the duration of the 30 -min infusion. Prior treatment with SRI 63441 was associated with complete inhibition of PAF-induced pulmonary vasoconstriction. Results are expressed as absolute values \pm SEM. ${ }^{*}, p<0.01$ vs baseline.

Table 1. Circulatory effects of sustained PAF infusion in newborn piglets $(n=10)^{*}$

\begin{tabular}{lccc}
\hline & $\begin{array}{c}\text { MAP } \\
(\mathrm{mm} \mathrm{Hg})\end{array}$ & $\begin{array}{c}\mathrm{SVRI} \times 10^{-3} \\
\left(\text { dynes } \mathrm{cm}^{-5} \cdot \mathrm{kg}\right)\end{array}$ & $\begin{array}{c}\mathrm{CI} \\
(\mathrm{mL} / \mathrm{kg} / \mathrm{min})\end{array}$ \\
\hline Baseline & $52 \pm 3$ & $29.3 \pm 2.0$ & $125 \pm 8$ \\
PAF 1 min & $54 \pm 3$ & $31.7 \pm 2.9$ & $121 \pm 10$ \\
PAF 3 min & $54 \pm 4$ & $32.6 \pm 3.2$ & $118 \pm 11$ \\
PAF 10 min & $55 \pm 4$ & $37.1 \pm 3.2$ & $106 \pm 9$ \\
PAF 30 min & $56 \pm 4$ & $34.6 \pm 3.3$ & $117 \pm 9$ \\
\hline
\end{tabular}

* Results are findings obtained 3 min after initiation of the first PAF infusion. Values are absolute values \pm SEM. MAP, mean arterial pressure; SVRI, systemic vascular resistance index; CI, cardiac index.

$0.02, \mathrm{PCO}_{2} 40 \pm 2 \mathrm{~mm} \mathrm{Hg}(5 \mathrm{kPa})$, and $\mathrm{PO}_{2} 109 \pm 7 \mathrm{~mm} \mathrm{Hg}(15$ $\mathrm{kPa})$ versus hypoxic $\mathrm{pH} 7.38 \pm 0.02, \mathrm{PCO}_{2} 39 \pm 1 \mathrm{~mm} \mathrm{Hg}(5$ $\mathrm{kPa})$, and $\left.\mathrm{PO}_{2} 33 \pm 1 \mathrm{~mm} \mathrm{Hg}(4 \mathrm{kPa})\right]$. Hypoxia increased PAP $(17 \pm 1$ to $32 \pm 2 \mathrm{~mm} \mathrm{Hg}, p<0.01)$ and PVRI $(6.4 \pm 0.9$ to $17.1 \pm 1.8$ dynes $\left.\mathrm{s} \mathrm{cm}^{-5} \cdot \mathrm{kg} \times 10^{-3}, p<0.01\right)$. All other measured parameters were unchanged. Neither SRI 63441 nor vehicle administration altered baseline blood gas content or hemodynamic parameters. PAF receptor antagonism with SRI 63441 failed to block hypoxia-induced increases in PAP (17 \pm 1 to 34 $\pm 1 \mathrm{~mm} \mathrm{Hg}, p<0.01)$ and PVRI $(5.7 \pm 1$ to $14.7 \pm 1$ dynes s $\left.\mathrm{cm}^{-5} \cdot \mathrm{kg} \times 10^{-3}, p<0.01\right)$.

Protocol 2. Effects of prolonged PAF infusion and reversibility with WEB 2086 or vehicle. Continuous infusion of PAF for 120 $\min (0.1 \mathrm{nmol} / \mathrm{kg} / \mathrm{min}, n=5)$ produced sustained increases in PAP $(14 \pm 1$ to $33 \pm 2 \mathrm{~mm} \mathrm{Hg}, p<0.05)$ and PVRI $(5 \pm 0.7$ to $25 \pm 3.5$ dynes $\left.\mathrm{s} \mathrm{cm} \mathrm{cm}^{-5} \cdot \mathrm{kg} \times 10^{-3}, p<0.05\right)$. Mean systemic
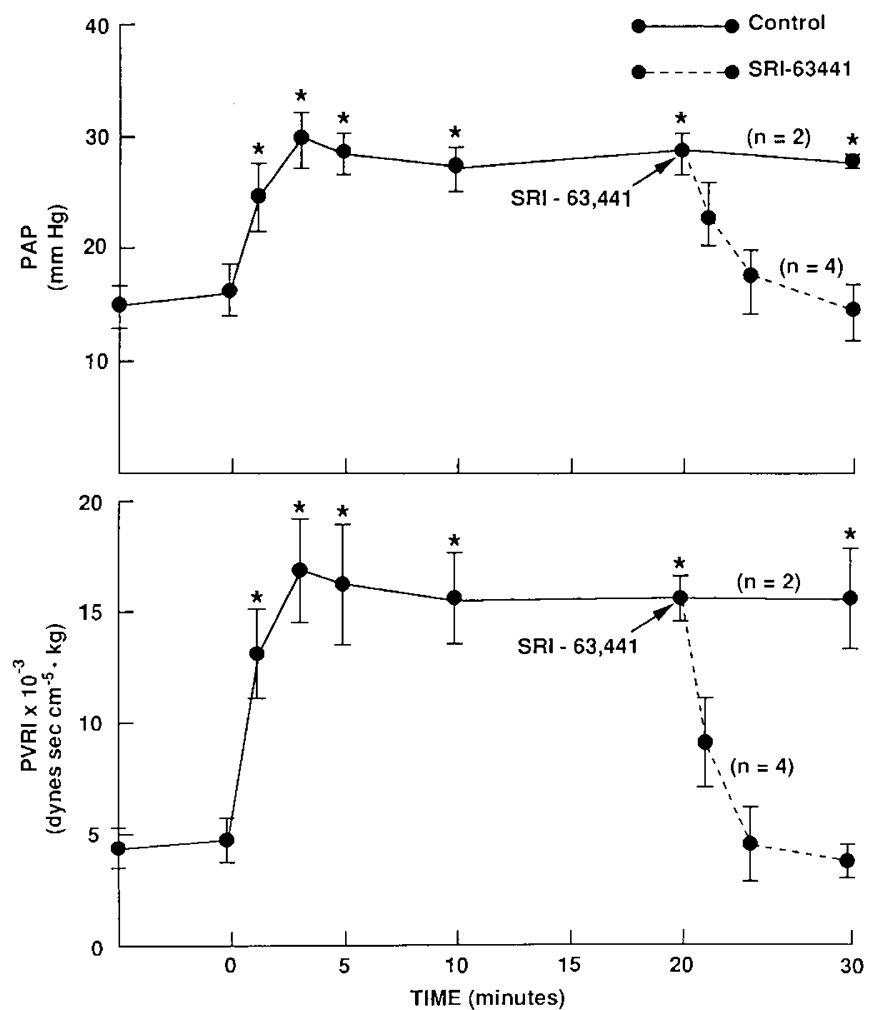

Fig. 2. Reversal of PAF-induced pulmonary vasoconstriction after SRI 63441 . PAF $(0.12 \pm 0.01 \mathrm{nmol} / \mathrm{kg} / \mathrm{min})$ was given to six animals pretreated with vehicle for SRI 63441 . This represented the second of the two PAF infusions. PAF dose again caused significant rises in PAP and PVRI. Injection of SRI 63441 at 20 min rapidly reversed PAFinduced pulmonary vasoconstriction. Values are means \pm SEM. ${ }^{*}, p<$ 0.01 vs baseline.

arterial pressure, systemic vascular resistance index, cardiac index, and coronary blood flow did not change in response to PAF administration. Treatment with WEB 2086 at 120 min caused PAP and PVRI to fall to near baseline levels within 15 min and to remain there until the conclusion of the study $(180 \mathrm{~min})$. In contrast, the PAF-induced rise in PAP and PVRI remained constant in vehicle-treated controls [PAP 20 versus $32 \pm 2 \mathrm{~mm}$ $\mathrm{Hg}$, PVRI 9.2 versus $26.0 \pm 1.9$ dynes $\mathrm{s} \mathrm{cm} \mathrm{cm}^{-5} \cdot \mathrm{kg} \times 10^{-3}$, WEB $2086(n=2)$ versus control $(n=3)$ at $180 \mathrm{~min}]$.

Effects of acute hypoxia after WEB 2086 or vehicle. As in protocol 1, hypoxemia increased PAP, PVRI, and cardiac index. PAF receptor antagonism with WEB 2086 failed to attenuate hypoxic pulmonary vasoconstriction (PAP 18 to $36 \mathrm{~mm} \mathrm{Hg}$, PVRI 7.1 to 22.7 dynes $\mathrm{s} \mathrm{cm}^{-5} \cdot \mathrm{kg} \times 10^{-3}$ ).

Effects of PAF in preconstricted pulmonary vascular bed. When PAF $0.1 \mathrm{nmol} / \mathrm{kg}$ i.v. bolus was given into the preconstricted (hypoxic) pulmonary vascular bed in vehicle-treated controls, PAP rose from $34 \pm 2$ to $41 \pm 2 \mathrm{~mm} \mathrm{Hg}$ and PVRI increased from $20.5 \pm 3.0$ to $33.4 \pm 3.2$ dynes s cm$~^{-5} \cdot \mathrm{kg} \times 10^{-3}$. PAFinduced pulmonary vasoconstriction was blocked by treatment with WEB 2086.

\section{DISCUSSION}

This study shows that the neonatal piglet's pulmonary vascular bed remains fully sensitive to sustained PAF infusion for up to $3 \mathrm{~h}$. Dose titration at outset rapidly identified an infusion rate (averaging $0.12 \mathrm{nmol} / \mathrm{kg} / \mathrm{min}$ ) sufficient to cause substantial pulmonary vasoconstriction-PAP rose $123 \%$ and PVRI rose $267 \%$-without destabilizing systemic or myocardial depressant effects. In the 10 piglets receiving a first PAF infusion, the level of pulmonary vasoconstriction established after $3 \mathrm{~min}$ persisted with no abatement for the remaining $27 \mathrm{~min}$ of the infusion 
(Fig. 1). These changes reversed completely when PAF infusion was halted. In the six piglets not given the PAF receptor blocker, SRI 63441 , this sequence of hemodynamic responses recurred during a second, identical PAF infusion (Fig. 2). Our results indicate that the rapid PAF receptor depletion found in response to repeated PAF exposure in isolated platelets $(17,18)$ or in adult sheep given bolus PAF (19) are not apparent with steady i.v. PAF administration to neonatal piglets. These findings differ from the PAF-induced pulmonary vasodilation reported in the rat (24) and fetal lambs (25). Moreover, there appears to be no cumulative PAF effect on cardiac output and no tendency for an initial PAF exposure to condition responses to a second PAF exposure. Such cumulative or long-lasting effects might be anticipated if PAF has caused rapid activation of endothelium or blood constituents, thereby triggering a variety of self-perpetuating inflammatory mechanisms. The total amount of PAF given over $30 \mathrm{~min}$, averaging $3.4 \mathrm{nmol} / \mathrm{kg}$, was far in excess of the amounts $(0.2-0.5 \mathrm{nmol} / \mathrm{kg})$ needed to induce shock in this (8) and other porcine preparations (11) when administered as a single i.v. bolus or a rapidly escalating infusion.

These results are limited by the specific dose and duration of PAF infusion selected for our studies. The higher PAF concentrations, and more prolonged ( $3 \mathrm{~h}) \mathrm{PAF}$ exposure, given to piglets in the second protocol failed to elicit tachyphylaxis to PAF. These data stand in marked contrast to those of Abman et al. (26) and Accurso et al. (27) where adaptation of tachyphylaxis to pharmacologic pulmonary vasodilators occurs in fetal lambs. Despite potential limitations, our data demonstrate that PAF can be administered to piglets by steady i.v. infusion in amounts sufficient to cause significant pulmonary vasoconstriction without rapid induction of either tachyphylaxis or hemodynamic collapse.

These results support the speculation that PAF plays a role in the pathogenesis of sustained neonatal pulmonary hypertension. In disease states where there is a persistent inflammatory focus, the activity of endothelial cells and leukocytes may lead to PAF release that is sustained for prolonged periods. Our model of continuous PAF infusion may simulate exacerbating conditions present in patients with neonatal pulmonary hypertension related to inflammatory disorders. The ongoing release of PAF may allow sufficient time for right ventricular adjustment to the developing pulmonary vascular dysfunction and avoid right heart failure. This hypothesis could be consistent with reported infusions of bacterial suspensions or exotoxins that caused significant pulmonary vasoconstriction but only slight systemic effects (2830).

Results with SRI 63 441, and WEB 2086, two structurally unrelated, highly selective, specific PAF-receptor antagonists (21-23), show that readily attainable, hemodynamically inert doses of this drug are effective in abolishing significant pulmonary vasoconstriction induced in piglets by i.v. PAF. When given to animals before PAF, SRI 63441 prevented any rise in mean PAP and PVRI. When either antagonist was given during prolonged PAF infusion, established pulmonary vasoconstriction completely reversed within $15 \mathrm{~min}$. Of particular interest is our finding that, when PAF is administered in the preconstricted (hypoxic) pulmonary vascular bed, further vasoconstriction occurs. These results refute the notion that the effects of PAF are dependent on the existing tone in the pulmonary circulation. In our neonatal piglet model, PAF reproducibly causes pulmonary vasoconstriction regardless of the initial level of PAP and PVRI. This study suggests that PAF must interact continuously with its receptors to maintain pulmonary vascular effects. That SRI 63441 is not a nonspecific vasodilator can be seen from data showing no difference in baseline systemic arterial pressure before and after this drug. Unaltered vasoconstriction during hypoxia showed that the pulmonary vasculature retained full responsiveness to constrictor interventions after SRI 63441 . This specificity indicates that PAF receptor blockade may be useful in treating those disorder in which PAF is a potential mediator of hemodynamic deterioration.

In addition to its potential role in inflammatory conditions, PAF has also been implicated in mediating hypoxic pulmonary vasoconstriction (28). Although our piglets readily developed pulmonary hypertension in response to hypoxic exposure, as described previously (8), this response was not attenuated by either SRI 63441 or WEB 2086. Therefore, PAF does not appear to be a major mediator of hypoxic pulmonary vasoconstriction in neonatal piglets.

In summary, our study has demonstrated the following: 1) the piglet pulmonary vascular bed remains fully sensitive to the constrictive effects of steadily infused PAF for up to $180 \mathrm{~min}$ and does not exhibit tachyphylaxis; 2) these constrictive effects are rapidly reversed by agonist discontinuation or receptor blockade, even late in the course of PAF infusion; 3) at appropriately low PAF doses, systemic cardiovascular function can be maintained despite the acute onset of sustained pulmonary vasoconstriction; 4) PAF-induced vasoconstriction is not dependent on the existing tone in the piglet pulmonary circulation; and 5) PAF is unlikely to mediate acute hypoxic pulmonary vasoconstriction in this preparation. These findings support the hypothesis that PAF can be a significant mediator of the sustained and injurious pulmonary vasoconstriction seen with inflammatory disorders in neonates, and they favor the possibility that PAF receptor blockade may represent a new approach to treatment of these disorders.

Acknowledgments. The authors thank Joan McMillen for her assistance in manuscript preparation.

\section{REFERENCES}

1. Fox WW, Duara S 1983 Persistent pulmonary hypertension in the neonate: diagnosis and management. J Pediatr 103:505-514

2. Perkin RM, Anas NG 1984 Pulmonary hypertension in pediatric patients. $J$ Pediatr 105:511-522

3. Heymann M, Hoffman JIE 1985 Persistent pulmonary hypertension syndromes in the newborn. In: Weir EK, Reeves JT (eds) Pulmonary Hypertension. Futura, New York, pp 45-71

4. Stenmark KR, James SL, Voelkel NF, Toews WH, Reeves JT, Murphy RC 1983 Leukotriene $C_{4}$ and $D_{4}$ in neonates with hypoxemia and pulmonary hypertension. N Engl J Med 309:77-80

5. Runkle B, Goldberg RN, Streitfeld MM, Clark MR, Buron E, Setzer ES Bancalari E 1984 Cardiovascular changes in Group B Streptococcal sepsis in the piglet: response to indomethacin and relationship to prostacyclin and thromboxane $\mathrm{A}_{2}$. Pediatr Res 18:874-878

6. Hammerman C, Lass N, Strates E, Komar K, Bui K-C 1987 Prostanoids in neonates with persistent pulmonary hypertension. J Pediatr 110:470-472

7. Bradley LM, Stambouly JJ, Czaja JF, Goldstein RE 1989 Influence of thromboxane $\mathrm{A}_{2}$ receptor antagonism on pulmonary vasoconstrictor responses. Pediatr Res 26:175-179

8. Bradley LM, Goldstein RE, Feuerstein GZ, Czaja JF 1989 Circulatory effects of PAF-acether in newborn piglets. Am J Physiol 256:H205-H212

9. Heymann, MA 1987 Postnatal regulation of the pulmonary circulation: a role for lipid mediators? Am Rev Respir Dis 136:222-224

10. Bessin P, Bonnet J, Apffel D, Soulard C, Desgroux L, Plas I, Benveniste J 1983 Acute circulatory collapse caused by platelet activating factor (PAF-acether) in dogs. Eur J Pharmacol 86:403-413

11. Laurindo FR, Goldstein RE, Davenport NJ, Ezra D, Feuerstein GZ 1989 Mechanisms of hypotension produced by platelet-activating factor. J Appl Physiol 66:2681-2690

12. Feuerstein G, Boyd LM, Ezra D, Goldstein RE 1984 Effect of platelet-activating factor on coronary circulation of the domestic pig. Am J Physiol 246:H466$\mathrm{H} 471$

13. Ezra D, Laurindo FR, Czaja JF, Snyder F, Goldstein RE, Feuerstein G 1987 Cardiac and coronary consequences of intracoronary platelet activating factor infusion in the domestig pig. Prostaglandins 34:41-57

14. Kenzora JL, Perez JE, Bergmann SR, Lange L 1984 Effects of acetyl glyceryl ether phosphorylcholine (platelet activating factor) on ventricular preload, afterload and contractility in dogs. J Clin Invest 74:1193-1203

15. Levi R, Burke JA, Guo ZG, Hattori Y, Hoppens CM, McManus LM, Hanahan DJ, Pinckard RN 1984 Acetyl glyceryl ether phosphorylcholine (AGEPC). A putative mediator of cardiac anaphylaxis shock in the guinea pig. Circ Res 54:117-124

16. Lefer AM, Mueller HF, Smith JB 1984 Pathophysiological mechanisms of sudden death induced by platelet activating factor. Br J Pharmacol 83:125130

17. Henson PM 1976 Activation and desensitization of platelets by platelet- 
activating factor (PAF) derived from lgE-sensitized basophils. I. Characteristics of the secretory response. J Exp Med 143:937-952

18. Henson PM, Pinckard RN 1977 Basophil-derived platelet-activating factor (PAF) as an in vivo mediator of acute allergic reactions: demonstration of specific desensitization of platelets to PAF during IgE-induced anaphylaxis in the rabbit. J Immunol 119:2179-2184

19. Toyofuku T, Kobayashi T, Koyama S, Kusama S 1988 Pulmonary vascular response to platelet-activating factor in conscious sheep. Am J Physiol 255:H434-H440

20. Eimerl J, Siren A-L, Feuerstein GZ 1986 Systemic and regional hemodynamic effects of leukotrienes $\mathrm{D}_{4}$ and $\mathrm{E}_{4}$ in the conscious rat. Am $\mathrm{J}$ Physiol 251:H700-H709

21. Handley DA, Tomesch JC, Saunders RN 1986 Inhibition of PAF-induced systemic responses in the rat, guinea pig, dog and primate by the receptor antagonist SRI-63,441. Thromb Haemost 56:40-44

22. Handley DA, Van Valen RG, Tomesch JC, Melden MK, Jaffe JM,Ballard FH, Saunders RN 1987 Biological properties of the antagonist SRI-63,441 in the $\mathrm{PAF}$ and endotoxin models of hypotension in the rat and dog. Immunopharmacology 13:125-132

23. Casals-Stenzel J 1987 Effects of WEB 2086, a novel antagonist of platelet activating factor, in active and passive anaphylaxis. Immunopharmacology 13:117-124

24. McMurtry IF, Morris KG 1986 Platelet-activating factor causes pulmonary vasodilation in the rat. Am Rev Respir Dis 134:757-762

25. Accurso F, Abman S, Worthen S, Henson PM 1986 Continuous platelet activating factor produces pulmonary vasodilation in the ovine fetus. Am Rev Respir Dis 11A (abstr)

26. Abman SH, Wilkening RB, Ward RM, Accurso FJ 1986 Adaptation of fetal pulmonary blood flow to local infusion of tolazoline. Pediatr Res 20:11311135

27. Accurso FJ, Wilkening RB 1988 Temporal response of the fetal pulmonary circulation to pharmacologic vasodilators. Proc Exp Biol Med 187:89-98

28. Prevost MC, Cariven C, Simon MF, Chap H, Douste-Blazy L 1984 Platelet activating factor (PAF-acether) is releated into rat pulmonary alveolar fluid as a consequence of hypoxia. Biochem Biophys Res Commun 119:58-63

29. Hammerman C, Komar K, Abu-Khudair H 1988 Hypoxic vs septic pulmonary hypertension. Selective role of thromboxane mediation. Am J Dis Child $142: 319-325$

30. Rojas J, Larsson LE, Ogletree ML, Brigham KL, Stahlman MT 1983 Effects of cyclooxygenase inhibition on the response to Group B Streptococcal toxin in sheep. Pediatr Res 17:107-110 